Original paper

\title{
How frequent is sleep-disordered breathing among Egyptian cirrhotic adults?
}

\author{
Nahla Elgammal' ${ }^{1}$ Tarik I Zaher ${ }^{1}$, Hoida Elkomy², Ahmed Attia Abdelmoaty' ${ }^{1}$ Mohamed Abdallah' ${ }^{1}$, Mohamed H Emara ${ }^{3}$ \\ 'Tropical Medicine Department, Faculty of Medicine, Zagazig University, Zagazig, Egypt \\ ${ }^{2}$ Chest Department, Faculty of Medicine, Zagazig University, Zagazig, Egypt \\ ${ }^{3}$ Hepatology, Gastroenterology and Infectious Diseases Department, Faculty of Medicine, Kafrelshiekh University, Kafr Elshikh, Egypt
}

\begin{abstract}
Aim of the study: Liver cirrhosis is an irreversible destructive liver disease that is associated with a wide range of complications. Among the recognized comorbidities of liver cirrhosis are sleep-disordered breathing (SDB), which is being more and more often described among cirrhotics. This study aimed to detect the prevalence of SDB among Egyptian post-viral cirrhotic adults.

Material and methods: This study enrolled 48 post-viral cirrhotic patients and 16 apparently healthy control subjects. All patients and controls were evaluated by thorough history taking, full clinical examination, laboratory investigations, the Epworth Sleepiness Scale questionnaire, the Berlin Questionnaire and polysomnography.

Results: Patients and controls were comparable as regards baseline demographics. Patients with liver cirrhosis had higher frequency of SDB compared to controls ( $56.2 \%$ vs. $12.5 \%, p=0.002)$. The most frequently encountered SBD patterns among cirrhotics were obstructive sleep apnea and apnea hypopnea index. Moreover, SDB was more severe among cirrhotics ( $25 \%$ were mild, $16.6 \%$ were moderate and $14.6 \%$ were severe obstructive sleep apnea - OSA) compared to the healthy controls (all were mild).

Conclusions: It seems that post-viral cirrhotic patients had a wide range of SDB with variable degrees of severity compared to the healthy controls.
\end{abstract}

Key words: sleep-disordered breathing, cirrhosis, obstructive sleep apnea, polysomnography.

\section{Address for correspondence}

Dr. Mohamed H Emara, Hepatology, Gastroenterology and Infectious Diseases Department, Faculty of Medicine, Kafrelshiekh University, Kafr Elshikh, 33516, Egypt, e-mail: emara_20007@yahoo.com

\section{Introduction}

Liver cirrhosis is a chronic, diffuse, progressive, degenerative disease that ends with liver parenchymal damage. Histologically, the lobules are structurally altered with dense peri-lobular connective tissue formation and often areas of regeneration develop. These areas of regeneration are described as cirrhotic nodules and they have a reduced blood supply resulting in impaired liver functions $[1,2]$.

Sleep-disordered breathing (SDB) is an umbrella term used to describe a number of disorders. These include abnormalities in the frequency, pattern, upper airway resistance and/or depth of breathing during sleep. It has been considered as a global health problem, because epidemiological studies have shown SDB to affect as many as $2 \%$ to $9 \%$ of middle-aged adults and more than $15 \%$ of older adults [3].

The most common SDB pattern is obstructive sleep apnea (OSA)/hypopnea syndrome. In addition, the following disorders are included under the term SDB syndromes: obesity hypoventilation syndrome (OHS), central sleep apnea (CSA), Cheyenne-Stokes respiration (CSR) and upper airway resistance syndrome (UARS) [4].

Obstructive sleep apnea is characterized by frequent episodes of upper airway collapse during sleep time resulting in reduction of blood oxygen saturation and 
usually terminated by arousals from sleep. Most patients awaken in the morning feeling tired and unrefreshed regardless of the duration of their time in bed [5].

In fact, the association between liver cirrhosis and breathing disorders has long been observed, e.g., sleep apnea is noted in ascetic patients. Moreover, the apnea hypopnea index ( $\mathrm{AHI}$ ) tends to increase with the increase in the amount of ascites. And the authors of one study concluded that a relationship exists between ascites and obstruction of the respiratory tract, especially during sleep [6].

This study aimed to estimate the prevalence of sleep-disordered breathing among Egyptian cirrhotic adults of viral etiology.

\section{Material and methods}

This multicenter cross sectional study was carried out in the Tropical Medicine Department and the sleep-disordered breathing unit of the Chest Department, Zagazig University Hospitals, Egypt and Hepatology, Gastroenterology and Infectious Diseases Department, Faculty of Medicine, Kafrelshiekh University, Egypt in the period from October 2017 to June 2019. The study was approved by the ethical committee board of Zagazig University in July 2017, and written, informed consent was obtained from each patient included in the study. Diagnosis of cirrhosis in the current study was achieved by clinical, biochemical and ultrasonography characteristics.

The study included 64 participants divided as follows: - case group (group I, $n=48$ ): patients with cirrhosis of viral etiology (43 cases were hepatitis $C$ virus $[\mathrm{HCV}]$ and 5 were hepatitis B virus $[\mathrm{HBV}])$; - control group (group II, $n=16$ ): 16 apparently healthy individuals.

Inclusion criteria: All cirrhotic adults ( $>18$ years old) who presented to the hepatology outpatient clinics of the participating centers were offered to participate in the study.

Exclusion criteria: Patients with the following medical problems were excluded from the current study: patients with overt hepatic encephalopathy, cerebrovascular stroke and those with substance abuse disorders, chronic chest diseases, e.g. chronic obstructive pulmonary disease (COPD), pleural effusion, non-viral cirrhosis, renal impairment or renal medical disease, recent gastrointestinal (GIT) bleeding, spontaneous bacterial peritonitis (SBP), hypothyroidism and patients with malignancies.

All participants were subjected to:

1. Complete history taking with special stress on:

- past history of hepatic encephalopathy (HE);
- respiratory symptoms suggestive of chest diseases, e.g. COPD;

- history of drug intake and particular habits, e.g. smoking, alcohol intake;

- sleep disturbance symptoms (excessive daytime sleepiness, insomnia at night, tiredness, difficulty waking up, snoring, choking, sleep walking, sleep talking and observed apnea. Sleep disturbance in this study was assessed by the followings:

- Epworth Sleepiness Scale (ESS) questionnaire: Used for evaluation of symptoms of excessive sleepiness. There are eight questions, each question taking scores of 0 to 3 . This scale evaluates the chance of dozing off or falling asleep in some situations. $0=$ would never doze, $1=$ slight chance of dozing, 2 = moderate chance of dozing and 3 = high chance of dozing. It is considered reliable if the patient's score is higher than 10 [3];

- Berlin Questionnaire: Used to evaluate sleep apnea in the patients. It contains 10 questions about risk factors of sleep apnea such as snoring, day time sleepiness, fatigue, obesity and hypertension [7].

2. Thorough physical examination including:

- general and local (abdominal and chest) examination;

- body mass index (BMI) assessment (weight in kg/ height $\mathrm{m}^{2}$ ).

3. Laboratory investigations:

- complete blood count (CBC), liver function tests, kidney function tests, prothrombin time, international normalized ratio (INR), random blood sugar (RBS),

- viral markers (HCVab, HBVsAg),

- thyroid function tests (thyroid-stimulating hormone - TSH, free T3, and free T4),

- arterial blood gases (ABG) analysis.

4. Electrocardiography (ECG).

5. Imaging investigations: Abdominal ultrasonography and plain chest $\mathrm{x}$-ray (postero-anterior view).

6. Polysomnography (PSG): A full-night polysomnographic sleep study was done using SOMNO screen plus (manufactured in Germany) in all patients. PSG is a comprehensive recording of the biophysiological changes that occur during sleep. It included electroencephalography (EEG), electro-oculography (EOG), electrocardiography (ECG), submental and anterior tibial electromyography (EMG), respiratory effort (abdominal and thoracic effort), nasal and oral airflow sensors and pulse oximetry for oxygen saturation. The PSG monitors many body functions including brain (EEG), eye movements (EOG), muscle activity or skeletal muscle activation (EMG) and heart rhythm (ECG) during sleep [8]. 


\section{Statistical analysis}

All data were collected, tabulated and statistically analyzed using SPSS 20.0 for Windows (IBM Corp., Armonk, NY, USA) and MedCalc 13 for Windows (MedCalc Software bvba, Ostend, Belgium). Quantitative data were expressed as the mean \pm SD and median (range), and qualitative data were expressed as absolute frequencies (number) and relative frequencies (percentage). Continuous variables were checked for normality using the Shapiro-Wilk test. Independent samples Student's $t$-test was used to compare two groups of normally distributed variables while the Mann-Whitney $U$ test was used for non-normally distributed variables. The one-way ANOVA test was used to compare more than two groups of normally distributed variables while the Kruskal-Wallis $\mathrm{H}$ test was used for non-normally distributed variables. All tests were two sided and a $p$-value $<0.05$ was considered statistically significant.

\section{Results}

\section{Study populations}

This study included 64 participants: 48 with post-viral cirrhosis (43 HCV and 5 were HBV) compared to 16 apparently healthy controls. There were no statistically significant differences among patients and controls regarding age, sex and BMI (Table 1).

\section{Laboratory parameters}

It is observed from the data shown in Table 2 that cirrhotic patients had derangements in their hepat- ic synthetic and excretory functions when compared with healthy individuals, and there were significant differences in the levels of serum albumin, INR, and serum bilirubin between the two groups.

Regarding blood oxygen $\left(\mathrm{O}_{2}\right)$ parameters, it is obvious that cirrhotic patients had lower $\mathrm{PaO}_{2}$ in their ABG compared to the normal individuals $(p<0.001)$.

\section{Characteristics of the cirrhotic group}

Characteristics of the cirrhotic group are shown in Table 3. The cirrhotic cohort comprised 48 patients, 16 in each Child class. It is clear that Child score and degree of ascites were higher in the advanced stage of liver cirrhosis. All patients with Child A cirrhosis were treated with direct acting antiviral therapy according to the guidelines of the Egyptian National committee for prevention and control of viral hepatitis (sofosbuvir + daclatasvir + ribavirin), while patients with Child B and C cirrhosis were not treated per the same protocol during the period of the study. The five patients with $\mathrm{HBV}$ infection all had $\mathrm{HBeAg}$ negative hepatitis and all were under treatment with entecavir.

\section{Sleep-disordered breathing}

The primary end point of the current study was to describe how frequent SDB is among post-viral cirrhotic adults. In this study cirrhotic patients had a higher prevalence rate of SDB compared to healthy controls and the difference was statistically significant (Table 4). There was a significant difference between

Table 1. Demographic and clinical data of patients and controls

\begin{tabular}{|c|c|c|c|c|c|c|}
\hline \multirow[t]{2}{*}{$\begin{array}{l}\text { Demographic } \\
\text { and clinical data }\end{array}$} & \multicolumn{2}{|c|}{$\begin{array}{l}\text { Control } \\
(n=16)\end{array}$} & \multicolumn{2}{|c|}{$\begin{array}{l}\text { Cirrhotic } \\
(n=48)\end{array}$} & \multirow[t]{2}{*}{ Test } & \multirow[t]{2}{*}{$\begin{array}{l}P \text {-value } \\
\text { (Sig.) }\end{array}$} \\
\hline & $n$ & $\%$ & $n$ & $\%$ & & \\
\hline \multicolumn{7}{|l|}{ Sex } \\
\hline Male & 12 & $75 \%$ & 27 & $56.2 \%$ & \multirow[t]{2}{*}{$1.772^{\S}$} & \multirow{2}{*}{$\begin{array}{c}0.183 \\
\text { (NS) }\end{array}$} \\
\hline Female & 4 & $25 \%$ & 21 & $43.8 \%$ & & \\
\hline \multicolumn{7}{|l|}{ Age (years) } \\
\hline Mean \pm SD & \multicolumn{2}{|c|}{$46.18 \pm 8.30$} & \multicolumn{2}{|c|}{$49.39 \pm 6.76$} & \multirow[t]{2}{*}{1.55} & \multirow{2}{*}{$\begin{array}{l}0.12 \\
\text { (NS) }\end{array}$} \\
\hline Median (range) & \multicolumn{2}{|c|}{$45.50(30-58)$} & \multicolumn{2}{|c|}{$50(37-62)$} & & \\
\hline \multicolumn{7}{|l|}{$\operatorname{BMI}\left(\mathrm{kg} / \mathrm{m}^{2}\right)$} \\
\hline Mean \pm SD & \multicolumn{2}{|c|}{$23.25 \pm 3.28$} & \multicolumn{2}{|c|}{$25.42 \pm 4.81$} & 1.67 & \multirow{2}{*}{$\begin{array}{l}0.09 \\
\text { (NS) }\end{array}$} \\
\hline Median (range) & \multicolumn{2}{|c|}{$21.75(17.50-29)$} & \multicolumn{2}{|c|}{$24(17-34)$} & & \\
\hline Underweight & 2 & $12.5 \%$ & 3 & $6.2 \%$ & $4.091^{\S}$ & \multirow{4}{*}{$\begin{array}{c}0.252 \\
\text { (NS) }\end{array}$} \\
\hline Normal weight & 10 & $62.5 \%$ & 22 & $45.8 \%$ & & \\
\hline Overweight & 4 & $25 \%$ & 15 & $31.2 \%$ & & \\
\hline Obese I & 0 & $0 \%$ & 8 & $16.7 \%$ & & \\
\hline
\end{tabular}

${ }^{\S}$ Chi-square test, $p<0.05$ is significant, Sig. - significance, NS - non-significant 
Table 2. Comparison between control and cirrhotic groups regarding biochemical parameters

\begin{tabular}{|c|c|c|c|c|}
\hline Complete blood picture & $\begin{array}{c}\text { Control } \\
(n=16)\end{array}$ & $\begin{array}{l}\text { Cirrhotic } \\
(n=48)\end{array}$ & Test & $\begin{array}{c}P \text {-value } \\
\text { (Sig.) }\end{array}$ \\
\hline \multicolumn{5}{|l|}{$\mathrm{Hb}(\mathrm{g} / \mathrm{dl})$} \\
\hline Mean \pm SD & $13.72 \pm 1.40$ & $10.06 \pm 2.07$ & \multirow[t]{2}{*}{$6.547^{*}$} & \multirow{2}{*}{$\begin{array}{c}<0.001 \\
(H S)\end{array}$} \\
\hline Median (range) & $13.90(10.80-15.40)$ & $10(5-14)$ & & \\
\hline \multicolumn{5}{|l|}{ Platelet count $\left(\times 10^{3} / \mathrm{ul}\right)$} \\
\hline Mean \pm SD & $283.50 \pm 91.37$ & $112.70 \pm 77.39$ & \multirow[t]{2}{*}{-5.078} & \multirow{2}{*}{$\begin{array}{c}<0.001 \\
(H S)\end{array}$} \\
\hline Median (range) & $270(170-440)$ & $102(14-386)$ & & \\
\hline \multicolumn{5}{|c|}{ Liver functions and blood gases } \\
\hline \multicolumn{5}{|c|}{ Total serum bilirubin $(0.3-1.2 \mathrm{mg} / \mathrm{dl})$} \\
\hline Mean \pm SD & $0.98 \pm 0.11$ & $2.70 \pm 1.54$ & \multirow[t]{2}{*}{$-4.412^{\circ}$} & \multirow{2}{*}{$\begin{array}{c}<0.001 \\
(H S)\end{array}$} \\
\hline Median (range) & $1(0.70-1.20)$ & $2.65(0.40-6.40)$ & & \\
\hline \multicolumn{5}{|l|}{ Albumin $(3.5-5 \mathrm{~g} / \mathrm{dl})$} \\
\hline Mean \pm SD & $4.18 \pm 0.39$ & $2.83 \pm 0.54$ & \multirow[t]{2}{*}{$9.087^{*}$} & \multirow{2}{*}{$\begin{array}{c}<0.001 \\
(H S)\end{array}$} \\
\hline Median (range) & $4.05(3.70-5)$ & $2.85(1.60-4)$ & & \\
\hline \multicolumn{5}{|l|}{ AST (5-40 u/l) } \\
\hline Mean \pm SD & $31.81 \pm 4.18$ & $59.72 \pm 57.38$ & \multirow[t]{2}{*}{$-2.924^{\bullet}$} & \multirow{2}{*}{$\begin{array}{c}0.003 \\
(S)\end{array}$} \\
\hline Median (range) & $32(25-38)$ & $48(15-304)$ & & \\
\hline \multicolumn{5}{|l|}{ ALT (5-35 u/l) } \\
\hline Mean \pm SD & $32.18 \pm 3.72$ & $33.25 \pm 17.96$ & \multirow[t]{2}{*}{$-0.365^{\circ}$} & \multirow{2}{*}{$\begin{array}{c}0.715 \\
\text { (NS) }\end{array}$} \\
\hline Median (range) & $32(25-39)$ & $32(11-111)$ & & \\
\hline \multicolumn{5}{|l|}{ INR } \\
\hline Mean \pm SD & $0.98 \pm 0.04$ & $1.39 \pm 0.33$ & \multirow[t]{2}{*}{$-5.401^{\bullet}$} & \multirow{2}{*}{$\begin{array}{c}<0.001 \\
(H S)\end{array}$} \\
\hline Median (range) & $1(0.90-1)$ & $1.30(0.90-2.40)$ & & \\
\hline \multicolumn{5}{|l|}{$\mathrm{pH}$} \\
\hline Mean \pm SD & $7.39 \pm 0.04$ & $7.41 \pm 0.06$ & \multirow[t]{2}{*}{$-0.984^{\bullet}$} & \multirow{2}{*}{$\begin{array}{c}0.325 \\
\text { (NS) }\end{array}$} \\
\hline Median (range) & $7.40(7.35-7.45)$ & $7.40(7.35-7.57)$ & & \\
\hline Normal & $100 \%$ & $81.2 \%$ & \multirow[t]{2}{*}{$3.491 \S$} & \multirow{2}{*}{$\begin{array}{c}0.097 \\
(\mathrm{NS})\end{array}$} \\
\hline Respiratory alkalosis & $0 \%$ & $18.8 \%$ & & \\
\hline \multicolumn{5}{|l|}{$\mathrm{PaO}_{2}(\mathrm{mmHg})$} \\
\hline Mean \pm SD & $95.56 \pm 1.36$ & $85.18 \pm 7.69$ & \multirow[t]{2}{*}{$-5.080^{\circ}$} & \multirow{2}{*}{$\begin{array}{c}<0.001 \\
(H S)\end{array}$} \\
\hline Median (range) & $95(94-98)$ & 86.50 (70-97) & & \\
\hline
\end{tabular}

*Independent samples Student's t-test, •Mann-Whitney U test, $p<0.05$ is significant, Sig. - significance, S - significant, NS - non-significant, HS - highly significant

cirrhotic and control groups as regard excessive daytime sleepiness evaluated by the Epworth Sleepiness Scale questionnaire $33.3 \%$ of cirrhotic patients experienced excessive daytime sleepiness (EDS) compared to $0 \%$ of the healthy controls, $p=0.007)$.

From the data obtained by polysomnography it is clear that cirrhotic patients had a significantly $(p=0.002)$ higher rate of SDB $(56.2 \%)$ in comparison to healthy controls $(12.5 \%)$. The most frequently encountered SDB patterns among cirrhotics were OSA and AHI. Moreover, the severity of SDB among cirrhotics was significantly higher $(p=0.018)$ than among healthy controls; $25 \%$ of cirrhotic patients had mild OSA, $16.6 \%$ had moderate OSA and $14.6 \%$ had severe OSA, while all the $12.5 \%$ of the healthy controls had mild OSA. Of note, there were no significant differences between control and cirrhotic groups as regard sleep efficacy and base $\mathrm{SpO}_{2}$ (Table 5).

\section{Discussion}

This study investigates an underestimated problem among cirrhotic patients, i.e. sleep-disordered breathing, and to the best of our knowledge, it is the first of its kind among Egyptian cirrhotic patients despite the high prevalence rates of liver cirrhosis. 
Table 3. Demographic and clinical data of the cirrhotic group

\begin{tabular}{|c|c|c|c|c|c|c|c|c|}
\hline \multirow{3}{*}{$\begin{array}{l}\text { Demographic } \\
\text { and clinical data }\end{array}$} & \multicolumn{6}{|c|}{ Cirrhotic patients } & \multirow[t]{3}{*}{ Test } & \multirow{3}{*}{$\begin{array}{c}P \text {-value } \\
\text { (Sig.) }\end{array}$} \\
\hline & \multicolumn{2}{|c|}{$\begin{array}{l}\text { Child A } \\
(n=16)\end{array}$} & \multicolumn{2}{|c|}{$\begin{array}{l}\text { Child B } \\
(n=16)\end{array}$} & \multicolumn{2}{|c|}{$\begin{array}{l}\text { Child C } \\
(n=16)\end{array}$} & & \\
\hline & $n$ & $\%$ & $n$ & $\%$ & $n$ & $\%$ & & \\
\hline \multicolumn{9}{|l|}{ Sex } \\
\hline Male & 9 & $56.2 \%$ & 10 & $62.5 \%$ & 8 & $50 \%$ & \multirow[t]{2}{*}{$0.508^{\S}$} & \multirow{2}{*}{$\begin{array}{c}0.776 \\
\text { (NS) }\end{array}$} \\
\hline Female & 7 & $43.8 \%$ & 6 & $37.5 \%$ & 8 & $50 \%$ & & \\
\hline \multicolumn{9}{|l|}{ Age (years) } \\
\hline Mean \pm SD & \multicolumn{2}{|c|}{$48.68 \pm 6.37$} & \multicolumn{2}{|c|}{$48.60 \pm 7.36$} & \multicolumn{2}{|c|}{$50.81 \pm 6.73$} & \multirow[t]{2}{*}{$0.515^{*}$} & \multirow{2}{*}{$\begin{array}{c}0.601 \\
\text { (NS) }\end{array}$} \\
\hline Median (range) & \multicolumn{2}{|c|}{$49.50(37-58)$} & \multicolumn{2}{|c|}{$47.50(37-62)$} & \multicolumn{2}{|c|}{$52.50(38-60)$} & & \\
\hline \multicolumn{9}{|l|}{ BMI $\left(\mathrm{kg} / \mathrm{m}^{2}\right)$} \\
\hline Mean \pm SD & \multicolumn{2}{|c|}{$25.97 \pm 4.65$} & \multicolumn{2}{|c|}{$24.35 \pm 4.50$} & \multicolumn{2}{|c|}{$25.94 \pm 5.36$} & \multirow[t]{2}{*}{$0.586^{*}$} & \multirow{2}{*}{$\begin{array}{c}0.561 \\
(\mathrm{NS})\end{array}$} \\
\hline Median (range) & \multicolumn{2}{|c|}{$24.50(18.50-33.50)$} & \multicolumn{2}{|c|}{$23.50(17.90-32)$} & \multicolumn{2}{|c|}{$27.75(17.80-34)$} & & \\
\hline Underweight & 0 & $0 \%$ & 1 & $6.2 \%$ & 2 & $12.5 \%$ & $4.932^{\S}$ & 0.553 \\
\hline Normal weight & 8 & $50 \%$ & 9 & $56.2 \%$ & 5 & $31.2 \%$ & & (NS) \\
\hline Overweight & 5 & $31.2 \%$ & 5 & $31.2 \%$ & 5 & $31.2 \%$ & & \\
\hline Obese I & 3 & $18.8 \%$ & 1 & $6.2 \%$ & 4 & $25 \%$ & & \\
\hline \multicolumn{9}{|l|}{ Ascites } \\
\hline No ascites & 14 & $87.5 \%$ & 4 & $25 \%$ & 0 & $0 \%$ & \multirow[t]{4}{*}{$39.877^{\S}$} & \multirow{4}{*}{$\begin{array}{c}<0.001 \\
(H S)\end{array}$} \\
\hline Mild ascites & 2 & $12.5 \%$ & 5 & $31.2 \%$ & 1 & $6.2 \%$ & & \\
\hline Moderate ascites & 0 & $0 \%$ & 7 & $43.8 \%$ & 10 & $62.5 \%$ & & \\
\hline Marked ascites & 0 & $0 \%$ & 0 & $0 \%$ & 5 & $31.2 \%$ & & \\
\hline \multicolumn{9}{|l|}{ Child score } \\
\hline Mean \pm SD & \multicolumn{2}{|c|}{$5.56 \pm 0.51$} & & 0.88 & & 0.80 & $42.700^{\circ}$ & $<0.001$ \\
\hline Median (range) & & & & & & 13) & & (HS) \\
\hline
\end{tabular}

*One-way ANOVA test, 'Kruskal-Wallis H test, ${ }^{\circledR}$ Chi-square test, $p<0.05$ is significant, Sig. - significance, HS - highly significant, NS - non-significant

In the current study the baseline demographics (age, sex and BMI) were comparable between cirrhotic and control groups (Table 1), eliminating their possible contribution to the prevalence of SDB among cirrhotics. Because obesity in particular is a major risk factor for SDB [9]. The most frequently reported patterns of SDB among our cohort were OSA and AHI, and this is consistent with most of the reports in the literature [10].

There were significant differences between the control and cirrhotic groups as regard excessive daytime sleepiness evaluated by the ESS questionnaire (33.3\% of cirrhotic patients experienced excessive daytime sleepiness compared to none of the healthy control) (Table 4). Actually, the data obtained from the questionnaire were reemphasized by polysomnography where $56.2 \%$ of cirrhotics significantly had SDB in comparison to $12.5 \%$ of healthy controls. This agrees with $\mathrm{Al}$ Enezi et al. [10], who found that $29.5 \%$ of patients with cirrhosis had EDS. In fact, different studies have report- ed variable prevalence rates of EDS among cirrhotics ranging from $18.5 \%$ to $38 \%$ [11-13]. It is logical that the prevalence rates of SBD differ with the methods used in assessment. Subjective tools, such as questionnaires, e.g. ESS and Berlin questionnaires, can be used to collect information on sleep quality and daytime complaints while objective methods such as PSG allow more precise assessment [14], and this was obvious in the current study; by questionnaire SBD is 33.3\% while by PSG the prevalence is higher at $56.2 \%$. This is due to the fact that patients, especially insomniacs, tend to underestimate their sleep quality. Therefore, it seems essential to rely on both subjective and objective methods to obtain a global picture of sleep among the patients [15].

In the current study not only the frequency but also the severity of SDB were significantly higher in cirrhotic patients compared to controls. We found that $25 \%$ of cirrhotic patients had mild OSA, $16.6 \%$ had moderate OSA and $14.6 \%$ had severe OSA, while 
Table 4. Comparison between control and cirrhotic groups regarding sleep disturbance

\begin{tabular}{|c|c|c|c|c|c|c|}
\hline \multirow[t]{2}{*}{ Sleep disturbance } & \multicolumn{2}{|c|}{$\begin{array}{l}\text { Control } \\
(n=16)\end{array}$} & \multicolumn{2}{|c|}{$\begin{array}{l}\text { Cirrhotic } \\
(n=48)\end{array}$} & \multirow[t]{2}{*}{ Test } & \multirow[t]{2}{*}{$\begin{array}{c}P \text {-value } \\
\text { (Sig.) }\end{array}$} \\
\hline & $n$ & $\%$ & $n$ & $\%$ & & \\
\hline \multicolumn{7}{|c|}{ Excessive daytime sleepiness } \\
\hline Absent & 16 & $100 \%$ & 32 & $66.7 \%$ & $7.111^{\S}$ & $0.007(S)$ \\
\hline Present & 0 & $0 \%$ & 16 & $33.3 \%$ & & \\
\hline \multicolumn{7}{|c|}{ Excessive daytime sleepiness } \\
\hline Mean \pm SD & \multicolumn{2}{|c|}{$0.62 \pm 0.88$} & \multicolumn{2}{|c|}{$7.14 \pm 5.37$} & $-4.861^{\bullet}$ & $<0.001(\mathrm{HS})$ \\
\hline Median (range) & \multicolumn{2}{|c|}{$0(0-3)$} & \multicolumn{2}{|c|}{$6(0-19)$} & & \\
\hline \multicolumn{7}{|l|}{ Berlin Questionnaire } \\
\hline Mean \pm SD & \multicolumn{2}{|c|}{$0.25 \pm 0.57$} & \multicolumn{2}{|c|}{$0.75 \pm 1$} & $-1.938^{\circ}$ & 0.053 (NS) \\
\hline Median (Range) & \multicolumn{2}{|c|}{$0(0-2)$} & \multicolumn{2}{|c|}{$0(0-3)$} & & \\
\hline Total score 0 & 13 & $81.2 \%$ & 26 & $54.2 \%$ & $4.267 \S$ & 0.234 (NS) \\
\hline Total score 1 & 2 & $12.5 \%$ & 13 & $27.1 \%$ & & \\
\hline Total score 2 & 1 & $6.2 \%$ & 4 & $8.3 \%$ & & \\
\hline Total score 3 & 0 & $0 \%$ & 5 & $10.4 \%$ & & \\
\hline \multicolumn{7}{|l|}{ Sleep apnea risk } \\
\hline No risk & 13 & $81.2 \%$ & 26 & $54.2 \%$ & \multirow[t]{3}{*}{$3.733 \S$} & \multirow{3}{*}{$\begin{array}{c}0.155 \\
\text { (NS) }\end{array}$} \\
\hline Low risk & 2 & $12.5 \%$ & 13 & $27.1 \%$ & & \\
\hline High risk & 1 & $6.2 \%$ & 9 & $18.8 \%$ & & \\
\hline
\end{tabular}

- Mann-Whitney U test, ${ }^{\S}$ Chi-square test, $p<0.05$ is significant, Sig. - significance, S - significant, NS - non-significant, HS - highly significant

Table 5. Comparison between control and cirrhotic groups regarding polysomnography

\begin{tabular}{|c|c|c|c|c|}
\hline \multirow[t]{2}{*}{ Polysomnography } & $\begin{array}{l}\text { Control } \\
(n=16)\end{array}$ & $\begin{array}{l}\text { Cirrhotic } \\
(n=48)\end{array}$ & \multirow[t]{2}{*}{ Test } & \multirow[t]{2}{*}{$\begin{array}{c}P \text {-value } \\
\text { (Sig.) }\end{array}$} \\
\hline & $\%$ & $\%$ & & \\
\hline \multicolumn{5}{|c|}{ Sleep-disordered breathing } \\
\hline Absent & $87.5 \%$ & $43.8 \%$ & \multirow[t]{2}{*}{$9.269 \S$} & \multirow{2}{*}{$\begin{array}{c}0.002 \\
(S)\end{array}$} \\
\hline Present & $12.5 \%$ & $56.2 \%$ & & \\
\hline \multicolumn{5}{|c|}{ Obstructive sleep apnea (OSA) } \\
\hline No OSA & $87.5 \%$ & $43.8 \%$ & \multirow[t]{4}{*}{$10.057 \S$} & \multirow{4}{*}{$\begin{array}{c}0.018 \\
(S)\end{array}$} \\
\hline Mild OSA & $12.5 \%$ & $25 \%$ & & \\
\hline Moderate OSA & $0 \%$ & $16.6 \%$ & & \\
\hline Severe OSA & $0 \%$ & $14.6 \%$ & & \\
\hline \multicolumn{5}{|c|}{ Apnea hypopnea index (AHI) } \\
\hline Mean \pm SD & $3.08 \pm 1.87$ & $11.73 \pm 11.36$ & \multirow[t]{2}{*}{$-3.001^{\bullet}$} & \multirow{2}{*}{$\begin{array}{c}0.003 \\
(S)\end{array}$} \\
\hline Median (range) & $2.75(1.10-7.90)$ & $7.50(1.30-36.10)$ & & \\
\hline \multicolumn{5}{|l|}{ Sleep efficacy (\%) } \\
\hline Mean \pm SD & $85.39 \pm 10.44$ & $85.08 \pm 11.55$ & \multirow[t]{2}{*}{$-0.163^{\circ}$} & \multirow{2}{*}{$\begin{array}{c}0.871 \\
(N S)\end{array}$} \\
\hline Median (range) & $88.90(54.90-97)$ & $88.90(56.80-99.10)$ & & \\
\hline \multicolumn{5}{|l|}{ Base $\mathrm{SpO}_{2}(\%)$} \\
\hline Mean \pm SD & $96.06 \pm 3.53$ & $94.77 \pm 3.35$ & \multirow[t]{2}{*}{$-1.600^{\circ}$} & \multirow{2}{*}{$\begin{array}{c}0.110 \\
\text { (NS) }\end{array}$} \\
\hline Median (range) & $97.50(88-99)$ & $95.50(85-99)$ & & \\
\hline \multicolumn{5}{|l|}{ Minimum $\mathrm{SpO}_{2}(\%)$} \\
\hline Mean \pm SD & $90 \pm 6.77$ & $84.75 \pm 10.05$ & \multirow[t]{2}{*}{$-2.256^{\circ}$} & \multirow{2}{*}{$\begin{array}{c}0.024 \\
(S)\end{array}$} \\
\hline Median (range) & $91(70-96)$ & $89(53-97)$ & & \\
\hline
\end{tabular}

- Mann-Whitney $U$ test, ${ }^{\S}$ Chi-square test, $p<0.05$ is significant, Sig. - significance, $S$ - significant, NS - non-significant 
$12.5 \%$ of healthy controls had mild OSA. This agrees with $\mathrm{Al}$ Enezi et al. [10], who found that patients with cirrhosis frequently have high risk of OSA especially among cirrhotic patients after $\mathrm{HCV}$ and diabetes.

The situation seems similar when sleep efficacy is evaluated by the ESS questionnaire, which is used in the current study; when cirrhotic patients were compared to healthy subjects, they had severe and a higher degree of EDS $[16,17]$.

The impact of SDB on blood oxygen tension was investigated among cirrhotics in this study. There was also a significant difference between control and cirrhotic groups as regard minimum $\mathrm{SpO}_{2}$. Cirrhotic patients experience a larger decrease in their $\mathrm{SpO}_{2}$ during sleep time than healthy controls do. But there were no significant differences between control and cirrhotic groups as regard sleep efficacy and base $\mathrm{SpO}_{2}$ (Table 5).

The question arises here why SDB was studied among cirrhotics, and the answer comprises two facts. First, cirrhotics had a variable degree of SDB, as confirmed in this study and in other studies [10, 18], and this influence their quality of life. Obstructive sleep apnea syndrome was reported as a complication of liver cirrhosis with ascites. Patients with OSA have 4 times higher prevalence of liver cirrhosis as compared to the general population [19]. Furthermore, the use of daytime sleepiness questionnaires found no differences in symptoms between patients with OSA and cirrhosis versus patients with OSA alone. Thus, obstructive sleep apnea should often be considered when a patient with liver cirrhosis complains of fatigue and sleep disturbances [18]. An important point here is that the patients enrolled in the current study were not referred for sleep study because they were complaining. Simply, they were evaluated for research purposes, and this confirms our assumption that SDB among cirrhotics is a problem underestimated by patients, relatives, and even physicians.

Second, it is surprising to us as clinicians to know that different forms of SDB, e.g. OSA, had deleterious effects on the liver although this had been reported in the literature with controversial conclusions. As it is becoming clear that OSA is an independent risk factor of liver injury, the early detection and initiation of treatment of sleep apnea now play a pivotal role in the management of liver cirrhosis [20,21]. OSA is associated with elevated alanine aminotransferase levels and a trend toward histologic evidence of progressive liver disease [22]. A small sample size study of 17 patients showed improvement in executive functions after continuous positive airway pressure (CPAP) treatment of OSA, which was in turn an independent predictor of concomitant liver cirrhosis [23]. An interesting study found that chronic intermittent hypoxia in mice with induced obesity is associated with liver fibrosis due to activation of pro-inflammatory pathways of liver fibrosis [24].

But what is the mechanism behind the association of SDB and liver cirrhosis?

Studies have reported elimination of OSA after ascites treatment, raising the possibility of the mechanical effect of ascites on diaphragmatic movement and reduction of the lung volume as a cause of OSA. Ascites induces diaphragmatic elevation, leading to a decreased functional residual capacity, and this can induce oxygen desaturation because of ventilation perfusion mismatch [25]. The occurrence of edema in the pharyngeal and laryngeal soft tissues in these patients could increase the collapsibility of the upper airways and is considered another possibility for occurrence of OSA among cirrhotic patients [26, 27].

Hypocapnia secondary to hormonal and chemical changes in liver cirrhosis may cause sleep apnea, although this is considered controversial [28]. An early study reported that patients with cirrhosis had markedly elevated melatonin levels during daytime hours. In addition, the time of onset of melatonin increase and the time at which melatonin levels peaked were consistently and significantly delayed in these patients [29].

This study has limitations. First, the number of patients recruited is small. Second, the study lacks both in depth analysis of the prior episodes of $\mathrm{HE}$ and testing for minimal HE, because HE by itself is associated with sleep disorders among cirrhotics [14] and one study concluded that prior HE may synergize with OSA in worsening sleep patterns in cirrhotics [18].

In conclusion, it seems that post-viral cirrhotic patients had a wide range of sleep-disordered breathing with variable severity detected by both questionnaires and polysomnography. This may be due to complex interactions between mechanical factors, hemodynamic factors, and vasoactive influences. Additional large studies are needed to confirm these findings in different causes of liver cirrhosis and better elucidate the mechanism underlying this relationship.

\section{Disclosure}

The authors report no conflict of interest.

\section{References}

1. Friedman SLM, Munoz SJ (eds.). Laboratory methods for evaluation of the patient with liver disease. Hepatology: A Textbook of Liver Disease. 4th ed. Sanders, Philadelphia 2004; 661-668.

2. Kumar VA, Fausto N. Robbins and Cotran. Pathologic Basis of disease. 7th ed. Elsevier Saunders, Philadelphia 2005; 877-938. 
3. Young T, Palta M, Dempsey J, et al. The occurrence of sleep-disordered breathing among middle-aged adults. N Engl J Med 1993; 328: 1230-1235.

4. Punjabi NM. The epidemiology of adult obstructive sleep apnea. Proc Am Thorac Soc 2008; 5: 136-143.

5. Sateia JM. International classification of sleep disorders - third edition: highlights and modifications. Chest 2014; 146: $1387-$ 1394.

6. Ogata T, Nomura M, Nakaya Y, Ito S. Evaluation of episodes of sleep apnea in patients with liver cirrhosis. J Med Invest 2006; 53: 159-166.

7. Thurtell MJ, Bruce BB, Rye DB, et al. The Berlin questionnaire screens for obstructive sleep apnea in idiopathic intracranial hypertension. J Neuroophthalmol 2011; 31: 316-325.

8. Sato M, Sasanabe R, Yamaguchi T, et al. Polysomnography. Nihon Rinsho 2015; 73: 980-984.

9. Leinum CJ, Dopp JM, Morgan BJ. Sleep-disordered breathing and obesity: pathophysiology, complications, and treatment. Nutr Clin Pract 2009; 24: 675-687.

10. Enezi AAl, Al-Jahdali F, Ahmed AE, et al. Symptoms of daytime sleepiness and sleep apnea in liver cirrhosis patients. Ann Hepatol 2017; 16: 591-598.

11. Bernsmeier C, Weisskopf DM, Pflueger MO, et al. Sleep disruption and daytime sleepiness correlating with disease severity and insulin resistance in non-alcoholic fatty liver disease: a comparison with healthy controls. PLoS One 2015; 10: e0143293.

12. Samanta J, Dhiman RK, Khatri A, et al. Correlation between degree and quality of sleep disturbance and the level of neuropsychiatric impairment in patients with liver cirrhosis. Metab Brain Dis 2013; 28: 249-259.

13. Mostacci B, Ferlisi M, BaldiAntognini A, et al. Sleep disturbance and daytime sleepiness in patients with cirrhosis: a case control study. Neurol Sci 2008; 29: 237-240.

14. Bruyneel M, Sersté T. Sleep disturbances in patients with liver cirrhosis: prevalence, impact, and management challenges. Nat Sci Sleep 2018; 10: 369-375.

15. Neu D, Mairesse O, Hoffmann G, et al. Sleep quality perception in the chronic fatigue syndrome: correlations with sleep efficiency, affective symptoms and intensity of fatigue. Neuropsychobiology 2007; 56: 40-46.

16. Heeren M, Sojref F, Schuppner R, et al. Active at night, sleepy all day - sleep disturbances in patients with hepatitis $\mathrm{C}$ virus infection. J Hepatol 2014; 60: 732-740.

17. Montagnese S, Middleton B, Skene DJ, et al. Night-time sleep disturbance does not correlate with neuropsychiatric impairment in patients with cirrhosis. Liver Int 2009; 29: 1372-1382.

18. Kappus MR, Leszczyszyn DJ, Moses L, et al. Effect of obstructive sleep apnea on the sleep architecture in cirrhosis. J Clin Sleep Med 2013; 9: 247-251.

19. Chou TC, Liang WM, Wang CB, et al. Obstructive sleep apnea is associated with liver disease: a population-based cohort study. Sleep Med 2015; 16: 955-960.

20. Jouët P, Sabaté JM, Maillard D, et al. Relationship between obstructive sleep apnea and liver abnormalities in morbidly obese patients: a prospective study. Obes Surg 2007; 17: 478-485.

21. Musso G, Cassader M, Olivetti C, et al. Association of obstructive sleep apnoea with the presence and severity of non-alcoholic fatty liver disease. A systematic review and meta-analysis. Obes Rev 2013; 14: 417-431.

22. Verhulst SL, Jacobs S, Aerts L, et al. Sleep-disordered breathing: a new risk factor of suspected fatty liver disease in overweight children and adolescents? Sleep Breath 2009; 13: 207-210.
23. Bajaj JS, Thacker LR, Leszczyszyn D, et al. Effects of obstructive sleep apnea on sleep quality, cognition, and driving performance in patients with cirrhosis. Clin Gastroenterol Hepatol 2015; 13: 390-397.e1.

24. Kang HH, Kim IK, Lee HI, et al. Chronic intermittent hypoxia induces liver fibrosis in mice with diet-induced obesity via TLR4/MyD88/MAPK/NF-kB signaling pathways. Biochem Biophys Res Commun 2017; 490: 349-355.

25. Crespo J, Cifrián J, Pinto JA, et al. Sleep apnea obstructive syndrome: a new complication previously undescribed in cirrhotic patients with ascites. Am J Gastroenterol 2003; 98: 2815-2816.

26. Nikaina I, Pastaka C, Zachou K, et al. Sleep apnoea syndrome and early stage cirrhosis: a pilot study. Eur J Gastroenterol Hepatol 2006; 18: 31-35.

27. Golpe R, Mateos A. Obstructive sleep apnea: a complication in cirrhotic patients with ascites? Am J Gastroenterol 2005; 100: 1421-1423.

28. Javaheri S, Almoosa KF, Saleh K, Mendenhall CL. Hypocapnia is not a predictor of central sleep apnea in patients with cirrhosis. Am J RespirCrit Care Med 2005; 171: 908-911.

29. Steindl PE, Finn B, Bendok B, et al. Disruption of the diurnal rhythm of plasma melatonin in cirrhosis. Ann Intern Med 1995; 123: 274-277. 